\title{
PASIÓN DE LA TIERRA Y ESPACIO: COSMOVISIÓN Y COSMOGONÍA
}

Miguel Pérez Delgado

\section{GÉNESIS Y CONCEPCIÓN}

No son Pasión de la Tierra ni Espacio libros paralelos, ni Vicente Aleixandre y Juan Ramón Jimenez son poetas que podamos considerar, siquiera, medianamente cercanos, ni en poéticas, ni en proyectos líricos, ni en trayectorias vitales, tan diferentes parecen ser ambos. Juan Ramón jamás consideró el surrealismo como moviemiento del que pudiera formar parte, aunque sí sabemos, por ejemplo, de su admiración por César Vallejo': «... Vallejo, que lo sacaba todo de dentro». Aleixandre, por el contrario, pasa por ser el mayor y mejor representante no sólo del surrealismo poético nacional, sino europeo también.

Sin embargo, en estos dos libros, Pasión de la Tierra y Espacio, parecen existir curiosas coincidencias, que veremos a continuación, y que unen más que separan a estas dos obras cumbres: una, primeriza, la de Aleixandre y, la otra, culminación de toda la producción juanramoniana, si seguimos a $\mathrm{A}$. de

1 Jiménez, J.R.; Tiempo y Espacio, Edaf, Madrid, 1986. Ed. de Arturo de Villar, pág. 115. 
Albornoz, una de las mejores conocedoras de la creación lírica de Juan Ramón ${ }^{2}$.

Comencemos por Espacio. Juan Ramón y Zenobia salen de Madrid el 22 de agosto de 1936, con pasaporte diplomático de la II República Española, tras el intento fallido de un anarquista de juzgarle; según el mismo nos cuenta en el 3. ${ }^{\text {er }}$ Fragmento de Espacio. Ya no volverá vivo a España. Desempeño una importante labor diplomática, en favor del gobierno de la República, por los Estados Unidos, Cuba y Puerto Rico. En marzo de 1939 ya se encuentran Zenobia y Juan Ramón instalados en Florida.

En 1941 comenzó a redactar Espacio. Durante cerca de tres años no había escrito poesía. El golpe de la guerra y del exilio fueron demasiado para un hombre como él, con una neurosis obsesiva desde muy joven (recordemos las que, gravemente, le afectaron durante los años 1910 al 13). También en este año inició su otro gran poema en prosa, Tiempo, que quedó inacabado. Juan Ramón, en carta a Enrique Díez-Canedo fechada el 6-VII-1943, explicaba la gestación de ambos poemas: «En La Florida empecé a escribir otra vez en verso. Antes, por Puerto Rico y Cuba, había escrito casi exclusivamente crítica y conferencias. Una madrugada me encontré escribiendo unos romances y unas canciones que eran un retorno a mi primera juventud, una inociencia última, un final lójico de mi última escritura sucesiva en España. La Florida es, como usted sabe, un arrecife llano y, por lo tanto, un espacio atmosférico que es y se siente inmensamente inmenso (...) una embriaguez rapsódica, una fuga incontenible empez 6 a dictarme un poema de espacio, en una sola estrofa de verso mayon ${ }^{4}$.

Hemos subrayado dos conceptos que creemos importantes: primero, que es la inmensa llanura de Florida el «espacio» que le va a inspirar el poema homónimo; segundo, el poema se concibió en un primer momento como escrito en verso. Así, fue siendo publicado fragmentariamente, hasta su versión definitiva en abril de 1954, aparecida en la revista madrileña «Poesía Española». En 1957, se publica una versión, ligeramente retocada en la Tercera Antolojía, preparada por Eugenio Florit con ayuda de Zenobia - hasta la muerte de ésta - ya que Juan Ramón había caído, desde 1954, en una profundísima depresión. Así podemos considerar que la elaboración de Espacio dura al menos trece años (1941-1954) o, si consideramos la edición de 1957, dieciseis.

2 Jiménez, J.R.; Nueva Antolojía, Península, Barcelona, 1983 (3." edición). Ed. de Aurora de Albornoz, pág. 72.

3 JiménEZ, J.R.; Tiempo y Espacio, Edaf, Madrid, 1986, pág. 137. Las citas subsiguientes de Espacio se realizan sobre esta edición de Arturo de Villar.

4 Citado por arturo de Villar, opus cit., pág. 15 y Aurora de Albornoz, opus cit, pág. 83. 
Larga génesis y sucesivas ediciones (aunque fragmentarias) y reelaboraciones.

Algo similar ocurrió con Pasión de la Tierra, como comprobaremos seguidamente. Pasión de la Tierra fue compuesto, según propia declaración de Aleixandre, a finales de los veinte; «Este libro de poemas en prosa fue escrito hace dieciocho años» (el poeta se encuentra en 1946) «en 1928-1929, y es la segunda obra del poeta» 5 . Vemos como la elaboración de Pasión de la Tierra viene a coincidir, cronológicamente, con Sobre los ángeles de Alberti (192728) y con Poeta en Nueva York de García Lorca (1929-30). Como sabemos es ésta, también, la época que podríamos denominar, utilizando un oxímoron, del surrealismo clásico. En 1924 había aparecido el primer Manifiesto Surrealista, en 1930 aparecerá el Segundo. Publican Breton, Aragon, Soupealt, Eluard. Se rodará Un perro andaluz, de Buñuel y Dalí. Pintan Arp, De Chirico, Miró, el mismo Dalí. También en los años veinte se conoce a Freud, a Joyce. En definitiva, el ambiente era surrealismo, destrucción, superación de lo anterior, tal como afirmaba Breton: «Le surréalisme, tel que je l' envisage, déclare assez notre non-conformisme absolu pour qu'il ne puisse être question de le traduire, au procès du monde réel, comme temoin à décharge» ${ }^{6}$. Fue, ya vemos, una autentica explosión, una marea que anegó la cultura occidental, que sacudió los cimientos sobre los que aquélla se sustentaba, al menos durante diez o quince años, y cuyos logros aún permanecen vivos en la conciencia de artistas e intelectuales.

No es el momento de discutir aquí, si fue el nacimiento del surrrealismo español independiente del francés y, por lo tanto, son dos camimos paralelos que se influyeron mutuamente, o no ${ }^{7}$. Lo que sí parece generalmente más aceptado es que el surrealismo español no se abandonó al automatismo psíquico tan facilmente como el francés, siguiendo la ya famosa definición de A. Breton: «Surrealisme. n. m. Automatisme psychique pur par lequel on se propose d'exprime, soit verbalement, soit par écrit, soit de toute autre manière, le fonctionement réel de la pensée»" 8 .

5 Citado en Aleixande, V.; Pasión de la tierra, Cátedra, Madrid, 1987. Edición de Grabrielle Morelli. pág. 20.

6 Bretón, A.; Manifestes du surréalisme, Gallimard, Cher (Francia), 1989, pág. 60.

7 Sobre el tema pueden consultarse: ILIE, P.; Los surrealistas españoles, Taurus, Madrid. 1972; ARANDA, Fco.; El surrealismo español, Lauren, Barcelona, 1981, sobre todo, los tres primeros capítulos; EARLE, P. y GULLÓN, G.; Surrealismo\&surrealismos. Latinoamérica y España, University of Pennsylvania, Filadelfia, (EE.UU.), 1977.

${ }^{8}$ BREtón, opus cit., pág. 36. 
Volviendo a Pasión de la Tierra, diremos que una primera edición fragmentaria se realizó en Méjico en 1935 (P.T.1), con el título que ya conocemos. Porque antes de ello, Pasión de la Tierra recibió otros. En un primer momento parece ser que se llamo Espadas como Labios, según declara Alejandro Duque Amusco, afirmación que recoge Morelli ${ }^{9}$. Más tarde, se pensó en intitularle $\mathbf{L a}$ evasión hacia el fondo (Recordemos que el último libro de Juan Ramón, Dios deseado y deseante, que podríamos considerar como la otra cara, la versificada, de Espacio, tiene una parte, la primera, denominada significativamente Animal de fondo. No será la última analogía).

En 1946 se realiza en «Adonais» la primera edición española del libro (P.T.2.), con siete poemas más que no habían sido publicados en la edición ultramarina de P.T.1. Asimismo se realizaron una serie de cambios, entre los que sobresalen los títulos de los poemas, generalmente, con un prístino propósito clarificador. En ediciones sucesivas V. Aleixandre irá recuperando otros cinco poemas. Parece que los siete poemas añadidos en P.T.2 se escribieron uno o dos años después de los restantes, según Morelli, o seis o siete, es decir, en 193435, según Amusco. Además de ello, parece claro que una obra que tan largo tiempo ha tardado en publicarse ha debido sufrir, si no cambios importantes, sí ligeros retoques por parte del autor. Así podemos afirmar que, si bien la obra estuvo escrita entre 1928-1929 y 193161935 (según se siga a Morelli o a Amusco) en sus fundamentos, no podemos aceptar como primera versión definitiva más que P.T.2, lo que supone una elaboración de dieciocho años (trece fueron los de Espacio).

Resumiendo, podemos concluir que ambas obras sufren un largo periodo de gestaciones sucesivas, de pequeños o grandes cambios y de ediciones fragmentarias, hasta que ven la luz las primeras versiones definitivas, siempre tras un periodo superior a la docena de años.

\section{ANÁLISIS FORMAL Y TEMÁTICO (minímamente)}

"¿Quién de nosotros no ha soñado, en sus días ambiciosos, con el milagro de una prosa poética, musical, sin ritmo ni rima, lo suficientemente flexible y

9 AleiXandre, V., Ed. de Morelli, opus cit., pág. 24. 
dura como para adaptarse a los movimientos líricos del alma, a las ondulaciones del ensueño y a los sobresaltos de la conciencia?» ${ }^{10}$.

Sirva esta cita de Baudelaire para situar la cuestión al referimos a la forma más externa de los dos libros a lo que nos enfrentamos. Ambos, en su última versión, son poemas en prosa, justamente igual que el libro de Baudelaire, cuya cita encabeza este apartado: Pequeños Poemas en Prosa. Si suprimimos aquellos de "sin ritmo", se parece mucho a lo siguiente: «...toda mi vida he acariciado la idea de un poema seguido (¿cuántos milímetros, metros, kilómetros?) sin asunto concreto, sostenido tan sólo por la sorpresa, el ritmo, el hallazgo, la luz, la ilusión sucesiva, es decir, por sus elementos intrínsecos, por su esencia...”" ${ }^{11}$, como afirmaba Juan Ramón sobre Espacio.

Aleixandre no se queda ni mucho menos atrás, aunque parece ser que sus motivaciones a la hora de elegir el poema en prosa son distintas. Así afirma: «La ruptura que este libro significaba tomó la más libre de las formas: la del poema en prosa. Es poesía «en estado naciente», con un mínimo de elaboración»12 (Pongamos, sin embargo, en cuarentena eso de «con un mínimo de elaboración»).

Como vemos, la idea de ambos poetas a la hora de acercarse a la forma externa, el poema en prosa, se debe, en última instancia, a la capacidad de aquél para adecuarse a cualquier intento expresivo, por su facilidad, utilizando un símil alfarero, de ser moldeado por el poeta, de adecuarlo a la forma interna del poema, para «adaptarse a los movimientos líricos del alma», como más arriba señalaba Ch. Baudelaire. A ello habría que añadir el componente novedoso y de ruptura formal que suponía el poema en prosa, infrautilizado en nuestra literatura, a diferencia, por ejemplo, de la francesa.

De esta forma, nos encontramos con que Espacio está compuesto por un largo poema en prosa dividido en tres fragmentos, sin los que «el poema es una larga tirada de palabras que parecen dictadas por el subsconciente» 13 .

El poema se configura como sigue:

10 Baudelaire, Ch.; Pequeños poemas en prosa. Los paraísos artificales, Cátedra, Madrid, 1986, pág. 46.

11 Citado por Aurora de Albornoz, opus cit., pág. 85.

12 Aleixandre, opus cit., pág. 182.

13 JULIA, M.; El universo de Juan Ramón Jiménez (un estudio del poema Espacio), Ediciones de la Torre, Madrid, 1989, pag. 41. 
ESPACIO

(tres estrofas)

(Por la Florida, 1941-1942, 1954)

FRAGMENTO PRIMERO

(Sucesión)

FRAGMENTO SEGUNDO

(Cantada)

FAGMENTO TERCERO

(Sucesión)

Como vemos, los fragmentos primero y tercero llevan el mismo subtítulo «(Sucesión)», mientras que el segundo figura a manera de intermedio de ambos. Lo podemos corroborar si observamos la extensión de cada fragmento. El fragmento primero ${ }^{14}$ consta de 358 líneas, el segundo de 58 y el tercero de 396. Observamos que el primer y el tercer fragmento tienen prácticamente la misma extensión, mientras que el segundo es mínimo en comparación con aquellos (aproximadamente 1/7). Asimismo, vemos como la suma del fragmento primero y segundo apenas sobrepasan al tercero (416 líneas por 396). Ello indica un profundo estudio y trabajo de la estructura del poema, lo que tratándose de Juan Ramón no nos puede extrañar.

En cuanto a Pasión de la Tierra se compone de un total ${ }^{15}$ de veintisiete poemas, distribuídos en siete apartados, o de 29 poemas en ocho apartados, si consideramos el apéndice final. Todos los poemas tienen título, general-

14 Sigo la edición de Arturo Villar.

15 Sigo la edición de G. Morelli. 
mente sintagmas nominales, salvo cinco en los que predomina el verbo, no obstante, copulativo. La extensión de dichos poemas varía entre las 38 líneas de «El mar no es una hoja de papel» y las 125 de «El solitario (Juego de naipes)». La generalidad fluctúa, sin embargo, en torno a las cincuenta o sesenta líneas.

Podemos terminar diciendo que ambas obras están compuestas por poesía en prosa, entendida como «composición (...) breve, muy limitada temáticamente, descriptiva casi siempre, que aspira a reproducir en prosa los efectos líricos del poema en verso. Su brevedad y su escaso desarrollo argumental distinguen al poema en prosa del cuento poético" ${ }^{16}$, y que se hallan sustentados por el ritmo (como cualquier otra forma lírica) ${ }^{17}$ y por una temática tratada de una forma extensa y no intensa. Y además, si el surrealismo está claro en Pasión de la Tierra, es más, es elemento constitutivo del libro, no es menos cierto que Espacio de J.R. Jiménez participa en muchos momentos, si no de surrealismo en estado puro, sí, al menos, de un surrealismo algo más ligero, más gaseoso . Está presente en la obra juanramoniana, de manera palpable, el flujo de consciencia y sobre ello afirma Guillermo Diaz-Plaja: «Es evidente que las fórmulas que propugnan la sinceridad (a veces brutal) de la expresión (hacia el subconciente o hacia la angustia) se apoyan en la estrofa irregular del verso no medido, en el verso no sujeto a ritmo alguno, capaz de dar libre fluencia de lo espontáneo. El mundo onírico, supra o subreal, debe ser explanado de acuerdo con el famoso «automatisme pur» (...) Así, el poeta desciende de su saber artístico para producirse en la más pura espontaneidad posible $^{18}$.»

Observaremos que, hasta el momento, las enormes diferencias que ambas obras parecían tener en un primer instante van diluyéndose. Veremos como también el tema las acerca. En los dos poemas el eje temático es la unión del hombre con el Cosmos, con la Naturaleza, entendida ésta como totalidad de lo creado; son, por lo tanto, dos cosmovisiones (aunque nos atrevemos a sugerir que se trata también de dos cosmogonías, en cuanto que intentan explicar el cosmos y, de alguna manera, su nacimiento también (Nacimiento Lírico, claro es). En Espacio existe una cosmovisión definida, lógicamente racionalizada, 421.

16 Paralso, I.; El verso libre hispánico (origenes y corrientes), Gredos, Madrid, 1985, página

17 Para el espinoso, a menudo, y poco claro, casi siempre, tema del ritmo se puede ver: LOPEZ EstradA, Fco.; Métrica española del siglo XX, Gredos, Madrid, 1987 (3.‘ reimpresión), capítulos 2 al 5 y Bousono, C.; Teoría del a expresión poética, Gredos, Madrid, 1985 (7." edición), capítulos XIII, XIV, XVII.

18 Citado por JuLía, opus cit., pág. 42. 
mientras que en Pasión de la Tierra, el lenguje surreal se corresponde con una cosmovisión igualmente informe, descoyuntada, caótica, sin límites precisos. Asistimos, por tanto, a dos modalidades cosmovisionarias.

Aleixandre va a entender el cosmos «como un mundo ambiyalente y dialéctico donde los contrarios no se excluyen porque sus substancia básica, al igual que la del cosmos primigenio, es una ${ }^{19}$ ».

En cuanto a Espacio, «es un momento de éxtasis prolongado en el que el poeta se hace consciente del cosmos y de su relación con $\mathrm{e}^{20}{ }^{2}$. Si bien, como hemos supradicto, ambas obras son las cosmovisiones de sus respectivos autores, estas cosmovisiones difieren: la de Aleixandre proteica, primigenia, mágica; la de Juan Ramón coherente, racional, más fría, a la que se podría aplicar al célebre aforismo de Leibniz. "Cum Deus calculat, mundus fit» (No en vano Kant y Einstein están presentes en su obra) ${ }^{21}$.

Así lo observamos:

«Lo más bello es el átomo último, el sólo indivisible, y que por serlo no es ya más, pequeño. Unidad de unidades es lo uno; iy qué viento más plácido levantan esas nubes menudas al cénit; qué dulce luz es esa suma roja única! Suma es la vida suma, y dulce!» (Esp., Frag. 1, pág. 125).

Juan Ramón está viendo, viviendo un mundo, un cosmos matemáticamente formado y en donde, por mor de esas matemáticas, todo tiene su función, su sentido, y su razón de ser.

Comparémosle con Aleixandre:

«Si saliéramos, si nos perdiéramos en el bosque, encontraríamos la luna cambiando, ajustando a la noche su corona abolida, prometiéndole una quietud como un gran beso. Pero los árboles se curvan, pesan, vacilan y no me dejan fingir que mi cabeza es más liviana que nunca, que mi frente es un arco por el que puede pasar nuestro destino.», (Pasión. págs. 159-160, «El mundo bien hecho»).

19 Novo Villaverde, Y.; «El surrealismo alexandrino. Pasión de la Tierra y Espadas como labios*, Insula, no 374-375, enero-febrero 1978, págs. 20-29.

20 Julia, opus cit., pág. 18.

21 Ibidem, pag. 71 y siguientes. 
Una y otra vez la inicial tendencia de Aleixandre a integrarse en el cosmos (igual que Juan Ramón), a re-integrarse en él, se ve truncada, frustrada por las mismas fuerzas atávicas que le llevan a querer formar parte de ese cosmos. -En definitiva, el libro no es más que un grito de angustia ante la pérdida de un paraíso pasado, una búsqueda de la infancia del mundo donde el poeta se reintegraria beato. -Así le hemos visto en el pasaje citado. La felicidad, la belleza de «una quietud como un gran beso», rápidamente se ve frustrada por medio de un enlace adversativo: «pero los árboles se curvan...».

Vemos, pues, como esa inicial tendencia de ambos poetas se va, poco a poco, convirtiendo en dos visiones diferentes del cosmos y, por consiguiente, de la vida.

Pero aún hay más. Espacio «es la historia trágica de un enamorado de la vida que no quiere morir», así «podemos entender las alusiones autobiográficas como artificio para lograr la eternidad. El poeta se inmortaliza doblemente: en la creación de poemas y, dentro del texto mismo, en las constantes referencias a su vida y a sus amigos. El yo poético (...) se vale de los medios que encuentra disponibles para aferrarse a esta vida y quedarse en ella eternamente ${ }^{22}$ ». Aleixandre, por su parte, intenta mostrarnos «una liberación que se llevaba a cabo a través de un envolvimiento directo del cuerpo (...) arrastrado y desgarrado por tendencias opuestas, que iban de un deseo de unión cósmica (...) a una necesidad más inmediata y circunstancial de auscultación y autodefinición personal ${ }^{23}$ ». Y esta búsqueda, esta persecución de lo primigenio esencial, el sanctasanctorum de la vida y de la muerte no es más que, en definitiva, un deseo, apenas reprimido, de ser, de perpetuarse, de trascender la muerte por medio de la afirmación amorosa que supone fusión con la totalidad de lo creado.

Es cuando menos, curioso, empero, las distintas maneras de presentarse el poeta, de re-presentarse en la obra. Así, como ya señalábamos, las referencias de Juan Ramón a su historia, a sí mismo son constantes: «No, ese perro que ladra al sol caído no ladra en el Monturrio de Moguer, ni cerca de Carmona de Sevilla, ni en la calle Torrijos de Madrid; ladra en Miami, Coral Gables, La Florida, y yo lo estoy oyendo allí, alli, no aquí, no aquí, allí, allí» (Esp., Frag. 1, pág. 128); «Me encontré al instalado, le ré, y me subí al rincón provisional, otra vez de mi soledad y mi silencio, tan igual en el piso 9...» (Esp., Frag. 2, pág. 133); «No era aquel auto disparado que rozó mi sien en el camino de Miami (...); ni aquella hélice de avión que sorbió mi ser completo y me dejó ciego, sordo, mudo en Barajas, Madrid... «(Esp., Frag. 3, pág. 137). En

22 Ibidem, pág. 16.

${ }^{23}$ Morelli, opus cit., pág. 14. 
Aleixandre, mientras, la presencia del cuerpo humano ${ }^{24}$ está, sin embargo, contrarrestada por la imposibilidad del poeta de definirse, de re-conocerse: «Aquí erguido estoy amenazando con mi as, que brilla con un fulgor opalino, enturbiando mis más íntimas sensaciones. Aquí estoy intentando quedarme conmigo mismo, ganarme a la partida ruidosa que se disputan los bosques de fuera, esas largas avenidas de viento que enredan las almas desordenadas bajo la luna. No me entiendo. Juego a ciegas.» (Pasión, «Fulguración del as», pág. 102). Creo que el pasaje es suficientemente significativo de la desorientación del poeta respecto de su propio yo, de la esencia de su ser. Algo absolutamente lógico si tenemos en cuenta lo ya dicho: a saber, que el poeta se enfrenta a un mundo caótico y desordenado, y donde él no deja de ser una pieza más de ese mundo sin sentido.

Tanto Juan Ramón como V. Aleixandre se enfrentan con el cosmos con el fin último de conocer, por mediación de la poesía (el poeta se vuelve a presentar como un demiurgo, como una sibila, como un iluminado), el ser del universo, la esencia de lo creado, en definitiva, con la intención de conocer el cómo y el porqué de las cosas y, por medio, de ese conocimiento, autoafirmarse, eternizarse. La diferencia es que mientras Juan Ramón se enfrenta a la realidad con un método, digamos que, hegeliano-tesis, antítesis-síntesis ( $Q u i e ́ n$ sabe más que yo, quién, qué hombre o qué dios, puede, ha podido, podrá decirme a mí qué es mi vida y mi muerte, qué no es?» TESIS; «Si hay quien lo sabe, yo lo sé más que ése, y si quien lo ignora, más que ése lo ignoro» ANTITESIS; «Lucha entre ese ignorar y este saber es mi vida, su vida, y es la vida» SINTESIS), V. Aleixandre lo hace desde la desesperación, desde la angustia, desde la irracionalidad a la «manera» nietszcheana («Ser de esperanza y lluvia que desciende del fondo del relámpago como un pecho partido. Piedra de cal y sangre que rompe sus vagidos contra la frente loca de luces aspeadas, de cruces fulgurantes hasta el hueso. Muero porque no sé si la forma percibe la claridad del sol, o si el fondo del mar puede encontrarse en un anillo. Porque tengo en la mano un pulmón que respira y una cabeza rota ha dado a luz a dos serpientes vivas»).

Hemos de aclarar, empero, una cuestión. El deseo de eternidad que anima a los poetas presenta diferentes resoluciones. En Juan Ramón ese deseo de eternidad se debe al miedo, al terror que siente hacia la muerte (recordemos su necrofobia), mientras que en Aleixandre la muerte se plantea como única forma de eternidad, en cuanto que la disolución del individuo en la tierra, le devuelve

24 MoRelli, G.; "La presencia del cuerpo humano en Pasión de la Tierra», Revista de Letras, 22, Universidad de Puerto Rico en Mayagüez, junio 1974, Trad. de A. Colinas. 
a su verdadera esencia, a su permanencia en el cosmos, en regreso al seno materno, como si fuera una actualización de la fase evangélica: «Pulvis eris et pulvis reverteris».

Veámoslo en J. R. Jiménez:

«Deering, vivo destino. Ya está Deering muerto y trasmutado. Deering Destino Deering, fuiste clarividencia mía de ti mismo, tú (...) Deering, sólo el Destino es inmortal, y por eso te hago a ti inmortal, por mi destino. Sí, mi Destino es inmortal y yo, que aquí lo escribo, seré inmortal igual que mi destino, Deering. Mi destino soy yo y nada y nadie más que yo; por eso creo en El y no me opongo a nada suyo, a nada mío, que El es más que los dioses siempre, el dios otro, rejidos, como yo por el Destino, repartidor de la substancia con la esencia» (Esp., Frag. 3, pág. 136).

$Y$ ahora en Aleixandre:

«La hora grande se acercaba en la bruma. La sala cabeceaba sobre el mar de cáscaras de naranja. Remaríamos sin entrañas si los pulsos no estuvieran en la muñecas. El mar es amargo. Tu beso me ha sentado mal al estómago. Se acerca la hora.

La puerta, presta a abrirse, se teñía de amarillo lóbrego lamentándose de su torpeza. Dónde encontrarle, oh sentido de la vida, si ya no hay tiempo. Todos los seres esperaban la voz de Jehová refulgente de metal blanco. Los amantes se besaban sobre los nombres. Los pañuelos eran narcóticos y restañaban la carne exangüe. Las siete y diez. La puerta volaba sin plumas y el ángel del Señor anunció a María. Que pase el primero» ( $\mathrm{Pa}$ sión., «La muerte o antesala de consulta», pág. 100).

Además de este tema principal (la visión del cosmos y la intención de fusionarse con él) existen una serie de subtemas. En Espacio son el amor, la vida/muerte, la obra y la Naturaleza. En Pasión de la Tierra, la dialéctica vida-muerte, el cuerpo humano, la mutilación y la violencia, el esteticismo y la Naturaleza. Si ordenamos los términos podemos formar la siguiente relación: 


\begin{tabular}{|l|l|}
\hline \multicolumn{1}{|c|}{ Espacio } & \multicolumn{1}{c|}{ Pasión de la tierra } \\
\hline Amor & Cuerpo humano (realización) \\
\hline Vida/muerte & $\begin{array}{l}\text { Dialéctica vida/muerte, } \\
\text { Mutilación-violencia }\end{array}$ \\
\hline Obra & Esteticismo \\
\hline \multicolumn{2}{|c|}{ Naturaleza } \\
\hline
\end{tabular}

El tema principal va desarrollándose, haciéndose por medio de los diversos subtemas, de manera que éstos, a la manera impresionista, serán los trazos donde se incardine el tema de las obras.

En Juan Ramón, el amor es el deseo del hombre por la mujer y viceversa, va a ser una energía que emana del universo y que une todo en él: «...que el amor es uno solo y vuelve cada día. ¿Qué es este amor de todo, cómo se me ha hecho en el sol, con el sol, en mí conmigo?» (Esp., Frag. 1, pág. 122), «Las flores nos rodean de voluptuosidad, olor, color y forma sensual; nos rodeamos de ellas, que son sexos de colores, de formas, de olores diferentes enviamos un sexo en una flor, delicado presente de oro de ideal, a un amor virjen, a un amor probado; sexo rojo a un glorioso; sexos blancos a una novicia; sexos violetas a la yacente (...) Amor, amor, amor (lo cantó Yeats), amor en lugar de escremento. ¿Asco de nuestro principio y nuestro fin; asco de aquello que más nos vive y más nos muere?» (Esp., Frag. 1, pág. 123); «...Eva y Adán, al fin y ya otra vez sin ropa, y la obra desnuda y la muerte desnuda, que tanto me atrajeron. Desnudez en la vida y desnudez la sola enternidad...» (Esp., Frag. 3, pág. 135).

Para V. Aleixandre, el erotismo será un tema recurrente en muchas obras. El amor, Eros, es en Aleixandre, a menudo, la única posibilidad de salvación, salvación que pasa ineludible por la muerte posterior: «Crecerán los magnolios. Mujer, tus axilas son frías. Las rosas serán tan grandes que ahogarán todos los ruidos. Bajo los brazos se pueden escuchar el latido del corazón de gamuza. ¡Qué beso! Sobre la espalda una catarata de agua helada te recordará tu destino. Hijo mío -La voz casi muda-. Pero tu voz es muy suave, pero la tos muy ronca escupirá las flores oscuras. Las luces se hincarán en tierra, arraigándose a mediodía. Te amo, te amo, no te amo. Tierra y fuego en tus labios saben a muerte perdida» (Pasión, «El amor no es relieve», Pág. 97). 
Observamos que en Aleixandre se cumple la siguiente ecuación: amor=muerte, amor=vida, luego vida=muerte, es decir, la única forma de vida es aquélla a la que se llega por medio de la muerte, que se logra en la unión amorosa, sexual, plena entre los amantes. (Comentamos de paso -más adelante lo trataremos en profundidad - como tanto para Juan Ramón como para V. Aleixandre las flores, las rosas, son una metáfora sexual).

Veamos otro ejemplo en el poema titulado «Ropa y serpiente» (pág. 112): $«$ Oh muerte! ¡Oh amor del mal, del bien, del lobo y del cordero...». También aquí el amor se muestra como única fuerza capaz de unir contrarios.

El tema de las rosas y el sexo-como ya señalábamos-aparece en varias ocasiones: «Las rosas blancas, las de metal pasado, las que oscurecen los ojos azules sin las marismas, encantan tardíamente la llegada de la noche. Están entre los labios pero no se notan. Oscurecen las yemas más remotas, sin que se sospeche. Tienen un perfume de frente, de grato escorzo de memoria, de aquello que pasó, que ya está ido, que era lo mismo exacto pero no se mide» (Pasión, «La forma y no el infinito», pág. 114).

También la mujer es tratada de forma parecida por ambos poetas:

\begin{tabular}{|l|l|}
\hline \multicolumn{1}{|c|}{ Espacio } & \multicolumn{1}{c|}{ Pasión de la tierra } \\
\hline $\begin{array}{l}\text { «.. la mujer, madre, hermana, amante! } \\
\text { (Frag. 1, pág. 124) }\end{array}$ & $\begin{array}{l}\text { «... amor mío, amparo, socorro o piedad» } \\
\text { («Reconocimiento», pág. 122) }\end{array}$ \\
\hline
\end{tabular}

La vida y la muerte reaparecen una y otra vez en las obras, es mas, son el tema recurrente, el hilo conductor, el argumento supremo. Ya Juan Ramón se lo plantea desde el principio: «i...qué es mi vida y mi muerte, qué no es? (Frag. 1, pág. 121); «La muerte (...) da igualdad a lo vivo, lo más y menos vivo, y lo menos parece siempre, con la muerte, más» (Frag. 1, pág. 127); «...formas de muerte o vida, forma de toma y deja, toma» (Frag. 3, pág. 137).

Existe en V. Aleixandre, además de todo lo ya dicho sobre el tema de la muerte, un continuo volver sobre la violencia, sobre la mutilación del cuerpo del hombre y hay, en concreto, un párrafo en J. Ramón y una simple línea en Aleixandre que presentan una muy clara alusión a la muerte. 


\begin{tabular}{|l|l|}
\hline \multicolumn{1}{|c|}{ Espacio } & \multicolumn{1}{|c|}{ Pasión de la tierra } \\
\hline $\begin{array}{l}\text { «Vi un tocón, a la orilla del mar neutro; } \\
\text { arrancado del suelo, era como un muer- } \\
\text { to animal; la muerte daba a su quietud } \\
\text { seguridad de haber estado vivo; sus ar- } \\
\text { terias cortadas con el hacha, echaban } \\
\text { sangre todavía» (Frag. 1, pág. 127). }\end{array}$ & $\begin{array}{l}\text { miento falta, decapitado por el hacha...» } \\
\text { («Fábula que no duele», pág. 152). }\end{array}$ \\
\hline
\end{tabular}

En cuanto a la naturaleza, aparece una y otra vez en ambas obras, convirtiéndose en un leiv-motiv, en una representación del cosmos, una metáfora de la creación, pero es tambien símbolo de libertad y pureza, como podemos ver en el último párrafo del fragmento primero de Espacio.

" Qué hermosa primavera nos aguarda en el amor, fuera del odio! ¡Ya soy feliz! ¡El canto, tú y el canto! El canto... Yo vi jugando al pájaro y a la ardilla, al gato y a la gallina, al elefante y al oso, al hombre con el hombre (...) ¡Espacio y tiempo y luz en todo yo, en todos y yo y todos! ¡Yo con la inmortalidad! (...) ¡Qué regalo del mundo, qué universo mágico, y todo para todos, para mí, yo! ¡Yo, universo inmenso, dentro, fuera de ti, segura inmensidad!» (Frag. 1, pág. 130).

También está presente en Pasión de la Tierra:

"¡ Oh viento, viento, perdóname estas barbas de hierba, húmeda pendiente que como un alud me sube hasta los ojos cerrados! ;Oh viento, viento, oreáme como al heno, písame sin que yo lo note! ¡Bárreme hasta ensalzarme de ventura! (»El solitario», págs. 147-148).

(Como podemos observar en ambos párrafos el anhelo de fusión en el cosmos es intenso).

Para Juan Ramón la obra, la Obra con mayúsculas tal como él la quería, es una manera de inmortalizarse. Y las referencias a su Obra están presentes en Espacio: «Sí, mi Destino es inmortal y yo aquí lo escribo...» (Frag. 3, pág. 136. El subrayado es nuestro); «Dentro de mí hay uno que está hablan- 
do, hablando, hablando ahora. No lo puedo callar, no se puede callar. Yo quiero estar tranquilo con la tarde, esta tarde de loca creación...» (Frag. 3, pág. 138).

En Aleixandre, esta presencia de la obra en el libro se manifiesta no de una manera explícita, clara, sino más bien implícita: es el caso del esteticismo. Como bien señala L.A. de Villena ${ }^{25}$, este esteticismo se materializa de dos maneras distintas: a) una tradicional, que supone detenerse a menudo en objetos y sensaciones bellas que afectan a la naturaleza, al hombre y al lenguaje, b) un esteticismo, eminentemente surrealista, que se complace en una especie de tumultuosidad subconciente.

Como hemos podido ver, al igual que el tema principal, en Pasión de la Tierra y en Espacio diferentes subtemas se repiten con ligeras variaciones. Ello nos llevará, más adelante, a plantearnos la posible influencia de Pasión de la Tierra (obra escrita en 1928-29) sobre Espacio (1941-1954).

Pero existen además una serie de analogías, motivos, pequeñas variaciones, que se repiten en una y otra obra.

\begin{tabular}{|l|l|}
\hline \multicolumn{1}{|c|}{ Pasión de la tierra } & \multicolumn{1}{|c|}{ Espacio } \\
\hline Identidad \\
\begin{tabular}{l|l} 
«Soy lo que soy. Mi nombre escondi- \\
do» (pág. 95).
\end{tabular} & $\begin{array}{l}\text { «Los dioses no tuvieron más sustancia } \\
\text { que la que tengo yo. Yo tengo, como } \\
\text { ellos, la sustancia de todo (...). No soy } \\
\text { presente sólo, sino fuga raudal de cabo } \\
\text { a fin» (Pág. 121). }\end{array}$ \\
\begin{tabular}{l|l} 
Sic et non \\
«Te amo, te amo, no te amo» (pág. 97)
\end{tabular} & $\begin{array}{l}\text { «Hermoso es no tener lo que se tiene» } \\
\text { (pág. 123). }\end{array}$ \\
«... y el angel del Señor anunció a Ma- \\
ría» (pág. 100).
\end{tabular}

${ }^{25}$ Aleixandre, V.; Pasión de la tierra, Orbis, Barcelona, 1984. Ed. a cargo de Luis Antonio de Villena, págs. 38 y siguientes. 


\begin{tabular}{|c|c|}
\hline Pasión de la tierra & Espacio \\
\hline \multicolumn{2}{|c|}{ Música } \\
\hline $\begin{array}{l}\text { «Esa misma canción que vuela, ésta que } \\
\text { estás tu cantando...» (pág. 101) } \\
\text { «.. la música callada...» (pág. 129) }\end{array}$ & $\begin{array}{l}\text { «... esa música que suena en el fondo de } \\
\text { todo, más allá...» (pág. 123). } \\
\text { «La música mejor es la que suena y ca- } \\
\text { lla...» (pág. 125) }\end{array}$ \\
\hline \multicolumn{2}{|c|}{ Libertad } \\
\hline $\begin{array}{l}\text { «Uno sentía bullir en los hombros una } \\
\text { anticipación de alas...» }\end{array}$ & $\begin{array}{l}\text { «... vientos como pájaros, pájaros igual } \\
\text { que flores...» (pág. 121). }\end{array}$ \\
\hline \multicolumn{2}{|c|}{ Aliteración } \\
\hline $\begin{array}{l}\text { «Sabré percibir los colores. Y los olo- } \\
\text { res» (pág. 107). }\end{array}$ & $\begin{array}{l}\text { «... nos rodean de voluptuosidad, olor, } \\
\text { color...» (pág. 123). }\end{array}$ \\
\hline \multicolumn{2}{|c|}{ El saber } \\
\hline «Lo ignoro todo» (pág. 109). & $\begin{array}{l}\text { «... y si quien lo ignora, más que ése lo } \\
\text { ignoro» (pág. 121). }\end{array}$ \\
\hline \multicolumn{2}{|c|}{ Enumeraciones caóticas } \\
\hline $\begin{array}{l}\text { «Oh amor del mal, del bien, del lobo y } \\
\text { del cordero; de ti, rojo callado que cre- } \\
\text { ces monstruoso hasta venir a un primer } \\
\text { plano, darme en la frente, destruirme! } \\
\text { Soy largo, largo...» } \\
\text { «Besos, labios, cadencias, soledades...» } \\
\text { (pág. 115). }\end{array}$ & $\begin{array}{l}\text { «Pasan vientos como pájaros, pájaros } \\
\text { igual que flores, flores, soles y lunas, } \\
\text { lunas, soles como yo, como almas, co- } \\
\text { mo cuerpos...». }\end{array}$ \\
\hline \multicolumn{2}{|c|}{ El más allá } \\
\hline $\begin{array}{l}\text { «La nada es un cuento de infancia que } \\
\text { se pone blanco cuando le falta el respi- } \\
\text { ro» (pág. 131). }\end{array}$ & $\begin{array}{l}\text { «... que llamamos en nuestro descon- } \\
\text { suelo, Edén, Oasis, Paraíso, Cielo, pero } \\
\text { que no lo es, y que sabemos que no lo } \\
\text { es, como los niños...» (pág. 122). }\end{array}$ \\
\hline
\end{tabular}




\begin{tabular}{|c|c|}
\hline Pasión de la tierra & Espacio \\
\hline \multicolumn{2}{|c|}{$\mathrm{El}$ nombre } \\
\hline $\begin{array}{l}\text { «Te nombro. Te nombro y te hago. Te } \\
\text { venzo y te lanzo» (pág. 133). }\end{array}$ & $\begin{array}{l}\text { «Esa cáscara vana, un nombre nada } \\
\text { más...» (pág. 144). }\end{array}$ \\
\hline \multicolumn{2}{|c|}{ Reduplicaciones } \\
\hline $\begin{array}{l}\text { «Cuando tú, tú, tú, tú, tú callas...» (pág. } \\
165 \text { ). }\end{array}$ & $\begin{array}{l}\text { «Y entonces, marenmedio, más mar, } \\
\text { eterno mar (...) no fue el Mediterráneo } \\
\text { azulazulazul...» (pág. 135). }\end{array}$ \\
\hline
\end{tabular}

Estos son unos cuántos ejemplos que nos muestran una indudable proximidad entre las actualizaciones lingüisticas y literarias de ambos textos.

\section{Los Sf́mbolos}

En Pasión de la tierra, los simbolos ${ }^{26}$ que dominan fundamentalmente son dos:

1. La serpiente (anillo, pitón, cobra). Representa la energía, la fuerza pura, la sabiduría. Es el principio femenino, lo primordial. Pero va a ser también la cara oculta de la Naturaleza, su aspecto maligno. Será, de esta suerte, un principio ambivalente: creación y destrucción. Es también, naturalmente, símbolo fálico y, por consiguiente, masculino.

2. La baraja (naipe, as, caballo, oros, espada, bastos). Son las distintas posibilidades de la vida, sus múltiples opciones y la partida de cartas

26 Sobre la simbología de Aleixandre sigo fundamentalmente a Morelli, «La presencia del cuerpo humano...»; L.A. de Villena en la introducción de Pasión de la Tierra de Orbis y a Valente, J.A.; «El poder de las serpiente», en Las palabras de la tribu. Siglo XXI de España, Madrid, 1971. 
sería el juego de la vida. Y el solitario será la reflexión del hombre sobre sí mismo.

Hay otra serie de símbolos como la sangre (la plenitud de la vida), la luna (elemento femenino y mudable), etc.

En Espacio ${ }^{27}$, los símbolos son plurivalentes, ya que un mismo símbolo puede expesar varias intuiciones. Los símbolos más representados son el mar (vida y muerte, paso el tiempo y la eternidad. Podríamos compararlo en determinadas situaciones con la serpiente aleixandrina), la mujer (amor, belleza, poesía), el árbol (la vida — cuando crecen - y la muerte —cuando están cortados-), el perro y el pájaro (eternidad, continuidad). De alguna manera, los símbolos que aparecen en Espacio son símbolos que habían aparecido en toda la Obra juanramoniana.

\section{CONCLUSIÓN}

Parece evidente, a tenor de lo visto hasta ahora, que existen evidentes relaciones entre las dos obras; y hace ya tiempo que dejamos de creer en «coincidencias" literarias, sobre todo, si son tan numerosas como éstas (sí sería, en cambio, casualidad que Juan Ramón en el fragmento tercero diga: «...de ámbito de abismo! ¡De ámbito de abismo!», uniendo así los títulos de las primeras obras de V. Aleixandre: Ambito y Pasión de la Tierra, que unidos, se iban a llamar La evasión hacia el fondo.

Habría, pues, que plantearse las posibles influencias de una obra en otra. El influjo de Juan Ramón es palpable en Ambito, la primera obra de Aleixandre, pero ¿y en Pasión de la Tiera?

A priori, hemos de considerar que fue Pasión de la Tierra la que influyo en Espacio, por ser aquélla obra anterior (recordemos: Pasión, 1928-1929; Espacio, 1941-1954). La primera publicación de Pasión de la Tierra fue realizada en Méjico en 1935. Pudo influir, por tanto, en Juan Ramón; más, si tenemos en cuenta, que a partir de 1936 reside en la zona del Caribe. La segunda edición de la obra aleixandrina es de "Adonais», en 1946. Tiene una mayor difusión. En esa época Juan Ramón estaba redactando el tercer fragmento. Sin embargo, negó haber leído Pasión de la Tierra.

27 JULIA, opus cit., pág. 63 y siguientes. 
En cuanto a Espacio, el primer fragmento del poema se publicó en verso libre en «Cuadernos Americanos», en 1943. La segunda parte se publico, asimismo, en verso libre, también en «Cuadernos Americanos», en 1944, Los dos fragmentos se volvieron a publicar en 1945. La obra completa se publica nueve años más tarde: evidentemente no influyó en Pasión. Aleixandre seguramente sí leyó los dos fragmentos primeros, pero en caso de existir esa influencia, se hubiera detectado en la segunda edición de Pasión (1946). Las variaciones entre P.T.1 y P.T.2 hubieran sido ya hace mucho tiempo analizadas y, sin embargo, nadie hasta ahora las ha descubierto, razón por la que suponemos que no existen.

Sólo restan dos soluciones: bien, fuentes comunes; nada extraño, si tenemos en cuenta el caudal de lecturas de ambos poetas; bien, que un mismo tema - la cosmovisión - les ha llevado por el mismo camino. ¿De qué manera podríamos averiguarlo? Mucho nos tenemos que, salvo algún «milagro», no lo podamos saber, aunque nos atrevemos a intuir que Juan Ramón -lector impenitente- sí llegó a conocer Pasion de la Tierra (No sería la primerra vez que Juan Ramón ocultase determinados hechos). Lo que haya de influencia directa en él es, ya, otra historia. 